\title{
Incidence and Risk Factors of Cardio-Cerebrovascular Event, Hospitalization, and Mortality in Patients Undergoing Regular Hemodialysis
}

Authors:
Ida Bagus Nyoman Mahendra, Yenny Kandarini, I Gde Raka Widiana
Division of Nephrology and Hypertension, Departement of Internal Medicine
Medical Faculty of Udayana University, Sanglah General Hospital-Denpasar
Editor
Lucky Aziza Bawazier

Received 15 October 2018, revised 7 April 2019, accepted 17 July 2019, published 1 August 2019

\begin{abstract}
Background: CKD patients undergoing regular HD experience a high rate of hospitalization and mortality compared to the general population. The main contributing factors were cardiovascular event and infection. In Indonesia, there has been no comprehensive and representative data available. This study aims to discover the incidence and risk factors of cardio-cerebrovascular events, hospitalization, and mortality, as well as the survival rate among patients undergoing regular HD at Sanglah general hospital Denpasar.
\end{abstract}

Methods: This study was an analytic retrospective cohort study conducted in Sanglah general hospital Denpasar from July $1^{\text {st }}$ to December $31^{\text {st }}$ 2017. Inclusion criteria were patients with CKD stage $5, \geq 18$ years old, and have undergone regular HD for at least 3 months. Patients with malignancy and requiring elective hospitalization were excluded. The Kaplan-Meier method was used to calculate the cumulative survival rate, and the log-rank test was used for extracting the risk factors that influenced the survival rate. Multivariate Cox regression analysis was used to test contributing risk factors towards composite outcomes (cardio-cerebrovascular events, hospitalization, and mortality) and mortality outcome. The risk factors contributors were declared with a value of relative risk and odds ratio adjusted with the confidence interval (CI) $95 \%$, the level of significance $(\alpha)$ was specified in the value of $p<0.05$.

Results: The composite outcome of incidence in 222 subjects within 6 months (184 days) was 18.09\% and mortality outcome was $8.11 \%$, with cardiovascular event as a major cause $(56 \%)$ of mortality outcome. The risk factors significantly contributed on

InaKidney | Vol. II | Is. 2| May - Aug 2019 composite outcome based on CKD etiology $(\mathrm{p}=0.03)$ were as follows: 1) Diabetic nephropathy ( $\mathrm{OR}=1.33$; CI 95\% 0.16-11.06); 2) Hypertensive nephrosclerosis (OR=0.98; CI 95\% 0.11 - 8.47); 3) Chronic pyelonephritis (OR=0.36; CI 95\% 0.05 - 2.74); 4) Chronic Glomerulonephritis $(\mathrm{OR}=0.23$; CI 95\% $0.02-2.66)$ and. Protective factor for mortality outcome were AV fistula $(\mathrm{p}=0.028$; OR $=0.46 ; 95 \%$ CI $0.23-0.92)$ and age $<52$ years old $(\mathrm{OR}=0.51$; CI $95 \% 0.26$ to $0.99 ; \mathrm{p}=0.047)$; AV fistula was also found to be a protective factor for composite outcome $(\mathrm{CCV}$, hospitalization, and death) $(\mathrm{OR}=0.37$; $\mathrm{CI} 95 \% 0.17-0.77 ; \mathrm{p}=0.01)$. The cumulative survival rate for composite outcome was $165.83 \pm 3.57$ days with the cumulative survival rate for mortality was $177.34 \pm 2.00$ days.

Conclusion: This study concluded that the incidence of mortality outcome was $8.11 \%$ within 6 months (184 days), with the cardiovascular event as the major cause (56\%), the significant protective factors for mortality outcomes were AV fistula and age, whereas the cumulative survival rate for mortality was $177.34 \pm 2.00$ days.

Keywords: CKD, regular HD, cardio-cerebrovascular, hospitalization, mortality.

Corresponding author:

IBN Mahendra; e-mail dr.ibmahendra@yahoo.com

\section{Background}

Patients with end-stage renal disease (ESRD) undergoing chronic hemodialysis (HD) have a significantly increased risk for hospitalization and mortality compared to the general population. ${ }^{1}$ One of the most prom- 
inent cause for hospitalization and mortality among HD patients is cardiovascular event; this population has 10-20 times higher risk for cardiovascular events compared to the general population after adjustments of age, gender, and the presence of type 2 diabetes. ${ }^{1,2}$ Cerebrovascular events were also frequent among HD patients, approximately 6 times higher than the general population after age adjustments. Another prevalent cause for increased mortality in HD patients was pneumonia; HD patients were at 10-times higher risk of pneumonia, where 1 in 5 patients develop pneumonia during the first year of dialysis. HD patients suffer more severe clinical manifestations of pneumonia and at 14-16 times higher risk of death., ${ }^{3,4}$

The National Kidney Foundation (NKF) classified chronic kidney disease (CKD) patients as a high-risk group for cardiovascular disease. This is due to the majority of these patients having both traditional and non-traditional risk factors for cardiovascular diseases. The traditional risk factors are the ones mentioned in the Framingham Heart Study such as age, male gender, tobacco use, hypertension, diabetes, physical inactivity, dyslipidemia, family history of cardiovascular disease, left ventricular hypertrophy, and menopause. The non-traditional risk factors or CKDassociated risk factors are related to the impairment of glomerular filtration rate such as anemia, oxidative stress and chronic inflammation, malnutrition, nitric oxide depression, hyperparathyroidism, vascular and myocardial calcification, electrolyte imbalance, fluid overload, and sympathetic over-reactivity. ${ }^{6,7,8}$ Other than increasing the risk of cardiovascular disease, the impaired glomerular filtration caused retention of toxic molecules known as the uremic toxins. These molecules induce both activation and deficiency of the immune system. ${ }^{2}$ The retention of uremic toxins caused increased activation of polymorphonuclear cells (PMNs) and monocytes/macrophages, causing increased production of reactive oxygen species (ROS) that leads to persistent inflammation but also 18 cause impaired phagocytosis function that leads to increased risk of infection. Adaptive immunity was also impaired, causing decreased $\mathrm{T}$ and $\mathrm{B}$ cells. Undergoing HD in itself also pose patients to risks such as dialyzer membrane incompatibility, dialysate impurity, endotoxin exposure, back-filtration, and vascular access infection. $^{2}$

There has been no comprehensive and representative data available in Indonesia regarding cerebro-cardiovascular events and infection among HD patients. This study aims to discover the incidence and risk factors of cardio-cerebrovascular events, hospitalization, and mortality, as well as the survival rate among patients undergoing regular HD at Sanglah General Hospital, Denpasar.

\section{Methods}

This study is a retrospective cohort study, done in Sanglah General Hospital, Denpasar from July $1^{\text {st }}$ December $31^{\text {st }} 2017$. Subjects were ESRD patients undergoing regular HD for at least 3 months before the study, aged $\geq 18$ years old. Subjects underwent twice a week hemodialysis session, with 4-5 hours duration for each session. Exclusion criteria were the presence of malignancy and hospitalization for elective procedures. All subjects have agreed to participate after signing a written informed consent. The number of samples needed was calculated for descriptive study with single population and dichotomous dependent variable, with the 6-month survival rate of HD patients was $72.3 \%$ according to the Indonesian Renal Registry (mortality rate $27.7 \%$ ). The minimum number of sample needed for the study was 171 , however, to anticipate a loss of data this study included $200 \mathrm{sub}$ jects. Baseline characteristics obtained from the subjects include etiology of CKD, age, gender, nutritional status (body mass index, albumin), blood pressure and hypertension grade, electrolyte imbalance (calcium 
and phosphate), anemia, and dialysis factors (the type of dialyzer and vascular access, and HD adequacy). The outcome measured were cerebro-cardiovascular events, hospitalization and its cause, and mortality by cause of death. Additional data obtained were the history of severe infection and the presence of hepatitis $\mathrm{B}$ and $\mathrm{C}$. The study protocol was approved by the Ethical Committee Sanglah General Hospital, approval number: 2439/UN.14.2/KEP/2017. Study data were analyzed using SPSS version 23.0 for Windows. The analysis for cumulative survival for the effect of risk factors on the composite outcome (cardio-cerebrovascular event, hospitalization, and death) was done using Kaplan-Meier bivariate analysis. The log-rank test was used to compare the cumulative survival curve between subjects with risk factors and subjects without risk factors. Statistical power was measured with $\mathrm{p}<0.05$. The correlation between certain risk factors with composite outcome and mortality were presented as adjusted odds ratio (OR) and relative risks (RR) with a confidence interval of $95 \%$. Cox's regression multivariate analysis was done to adjust other risk factors for the composite outcome of cumulative survival and mortality outcome. Total life sustainability and cerebro-cardiovascular outcome hazard were analyzed using survival curve. Data of proportion and frequency was presented as percentages with 95\% confidence interval. Continuous data with normal distribution will be presented as mean value with standard deviations, whereas abnormally distributed data will be presented as median value with interquartile range.

\section{Results}

During the study period, 222 subjects met the inclusion and exclusion criteria. There were 40 (18.09\%) subjects with composite outcome (CV incidence, hospitalization, and death). Two subjects underwent kidney transplantation procedures at Sanglah HospiInaKidney | Vol. II | Is. 2| May-Aug 2019 tal Denpasar. The basic characteristics of the research subjects are presented in Table 1.

Of the 40 subjects who experienced composite outcome, $22(55 \%)$ subjects experienced hospitalization and $18(45 \%)$ subjects died. Based on the causes of hospitalization from 22 subjects, 13 (59\%) of the subjects were treated because of healthcare-associated pneumonia (HCAP), while 5 (23\%) subjects were treated because of the incidence of CV, 4 (18\%) subjects due to other causes. Whereas from 18 subjects that died, $10(56 \%)$ of the subjects died of cardiovascular (CV) events and 8 (44\%) subjects due to septic shock. There were no deaths due to cerebrovascular events.

In 6 months there were 40 composite outcomes (CV incidence, hospitalization, and death) of $222 \mathrm{CKD}$ patients who underwent regular HD at Sanglah General Hospital in Denpasar, so composite outcome incidents were $18.09 \%$, with cumulative average survival time (composite output) of 164,83 \pm 3.57 days (Figure 1a). There were 18 deaths from 222 HD patients who underwent regular HD at Sanglah Hospital Denpasar, the incidence of death outcomes was $8.11 \%$, and with cumulative average survival time (the outcome of death) for $177.34 \pm 2.00$ days (Figure $1 b$ ).

The cumulative survival for mortality in patients with CKD who underwent regular HD at Sanglah General Hospital Denpasar based on etiology: 1) Diabetic nephropathy was $73 \%$ with an average survival of $165.87 \pm 11.34$ days, $p \log$ rank $=0.05 ; 2$ ) Hypertension was $86.7 \%$ with a mean survival of $180.36 \pm 2.74$ days, $\mathrm{p} \log$ rank $=0.05$; 3 ) Chronic pyelonephritis is $93.5 \%$ with an average survival of $176.71 \pm 2.42$ days, $\mathrm{p} \log$ rank $=0.05$; 4) Chronic glomeruonephritis is $94.4 \%$ with a mean survival of $175.17 \pm 12.14$ days, $p$ $\log$ rank $=0.05 ; 5$ ) Obstructive nephropathy of $100 \%$ with a mean survival of $184.00 \pm 0.00$ days, $p$ log rank $=0.05$ (Figure $2 \mathrm{~b})$. 
Table 1. Subjects' baseline characteristics

\begin{tabular}{|c|c|}
\hline Baseline Characteristics & $\begin{array}{c}\text { Mean } \pm \text { SD or } \\
\text { Percentage }\end{array}$ \\
\hline Age (years) & $51.11 \pm 12.42$ \\
\hline Male/Female & $144(65 \%) / 78(35 \%)$ \\
\hline Body mass index $\left(\mathrm{Kg} / \mathrm{m}^{2}\right)$ & $22.42 \pm 3.60$ \\
\hline Weight (kg) & $59.45 \pm 11.21$ \\
\hline Height (m) & $1.62 \pm 0.07$ \\
\hline Systolic blood pressure (mmHg) & $132.93 \pm 22.19$ \\
\hline Diastolic blood pressure (mmHg) & $81.71 \pm 11.25$ \\
\hline Total cholesterol (mg/dL) & $157.83 \pm 38.67$ \\
\hline $\mathrm{LDL}(\mathrm{mg} / \mathrm{dL})$ & $95.96 \pm 34.02$ \\
\hline HDL (mg/dL) & $36.73 \pm 11.94$ \\
\hline $\mathrm{TG}(\mathrm{mg} / \mathrm{dL})$ & $151.24 \pm 98.71$ \\
\hline Uric acid (mg/dL) & $7.80 \pm 1.73$ \\
\hline Albumin (mg/dL) & $3.91 \pm 0.39$ \\
\hline Natrium (mmol/L) & $137.40 \pm 3.98$ \\
\hline Kalium (mmol/L) & $5.01 \pm 0.94$ \\
\hline Calcium (mg/dL) & $8.92 \pm 0.84$ \\
\hline Phosphate(mg/dL) & $5.76 \pm 1.96$ \\
\hline Hemoglobin (g/dL) & $10.97 \pm 4.19$ \\
\hline Serum iron $(\mu \mathrm{g} / \mathrm{dL})$ & $66.53 \pm 37.78$ \\
\hline TIBC $(\mu \mathrm{g} / \mathrm{dL})$ & $203.04 \pm 44.43$ \\
\hline $\mathrm{TS}(\%)$ & $33.84 \pm 20.32$ \\
\hline Ferritin (ng/mL) & $750.05 \pm 451.43$ \\
\hline Dialysis vintage (months) & $52.48 \pm 33.80$ \\
\hline Urea pre-HD (mg/dL) & $67.98 \pm 18.53$ \\
\hline Urea post-HD (mg/dL) & $22.11 \pm 12.94$ \\
\hline Body weight pre-HD (kg) & $61.06 \pm 12.08$ \\
\hline Body weight post-HD (kg) & $58.47 \pm 11.87$ \\
\hline UFG (L) & $2.71 \pm 1.06$ \\
\hline URR (\%) & $73.43 \pm 11.23$ \\
\hline $\mathrm{Kt} / \mathrm{V}$ & $1.66 \pm 0.24$ \\
\hline
\end{tabular}

LDL: low-density lipoprotein; HDL: high-density lipoprotein; TG: triglyceride; TIBC: total pr iron-binding capacity; TS: transferrin saturation; HD: hemodialysis; UFG: ultra-filtration goal; URR: urea reduction ratio; K: dialyzer clearance of urea; t: dialysis duration time; v: volume of distribution for urea in the body.
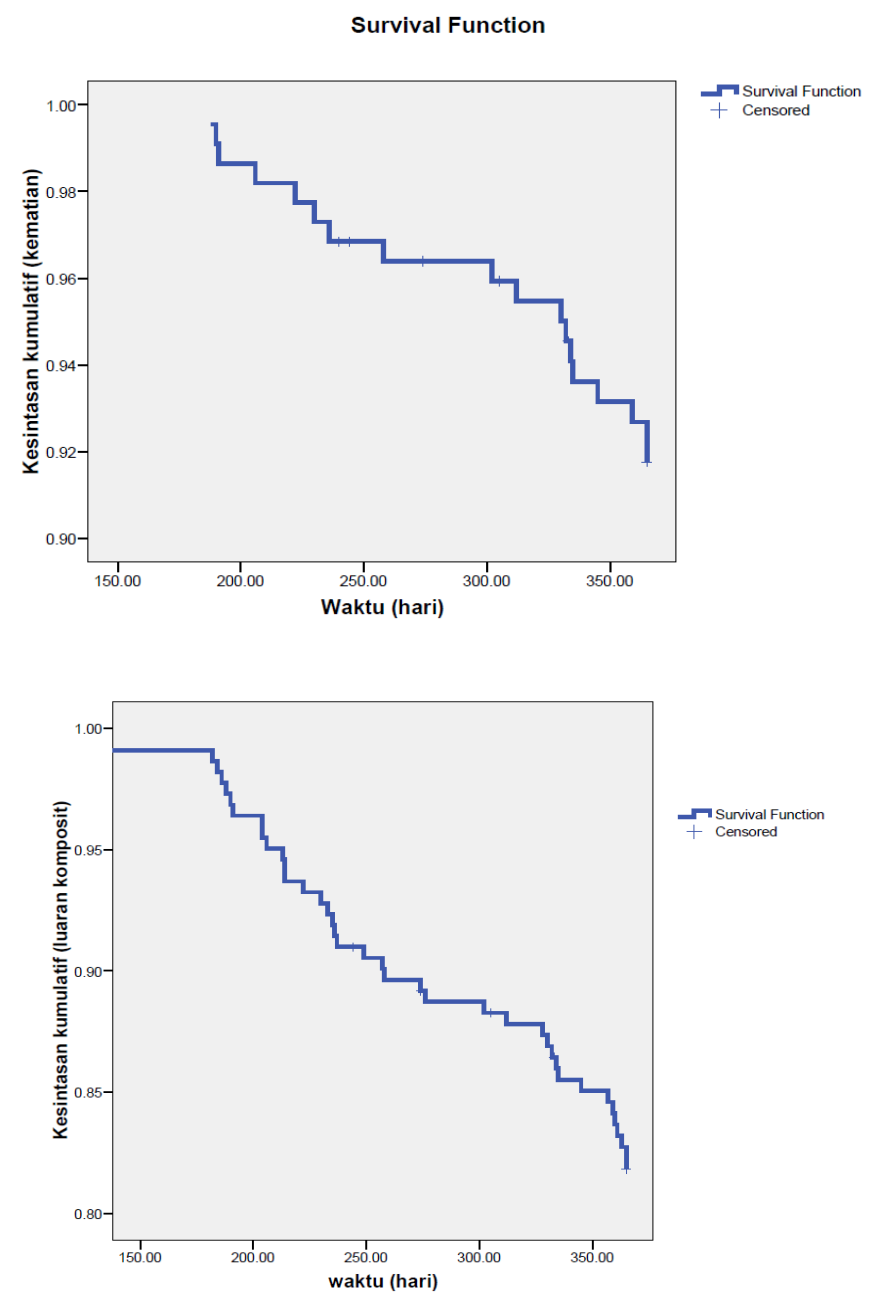

Figure 1. a. The cumulative survival for the composite outcome and b.mortality outcome in regular HD patients at Sanglah Hospital Denpasar

The cumulative survival for composite outcomes in CKD patients undergoing regular HD at Sanglah Hospital Denpasar based on etiology were as followed: 1) Diabetic nephropathy by $60 \%$ with an average survival of $157.20 \pm 12.41$ days, $p \log$ rank $=0.07 ; 2$ ) Hypertension is $66.7 \%$ with a mean survival of 150.09 \pm 16.08 days, $\mathrm{p} \log$ rank $=0.07$; 3 ) Chronic pyelonephritis is $84.7 \%$ with a mean survival of $165.52 \pm 4.19$ days, $\mathrm{p} \log$ rank $=0.07$; 4) Chronic glomerulonephritis is $88.9 \%$ with a mean survival of $173.98 \pm 8.72$ days, $\mathrm{p} \log$ rank $=0.07$; 5) Obstructive nephropathy of $75.0 \%$ with a mean survival of $182.75 \pm 1.08$ days, $p$ $\log$ rank $=0.07$ (Figure $2 \mathrm{a})$. 

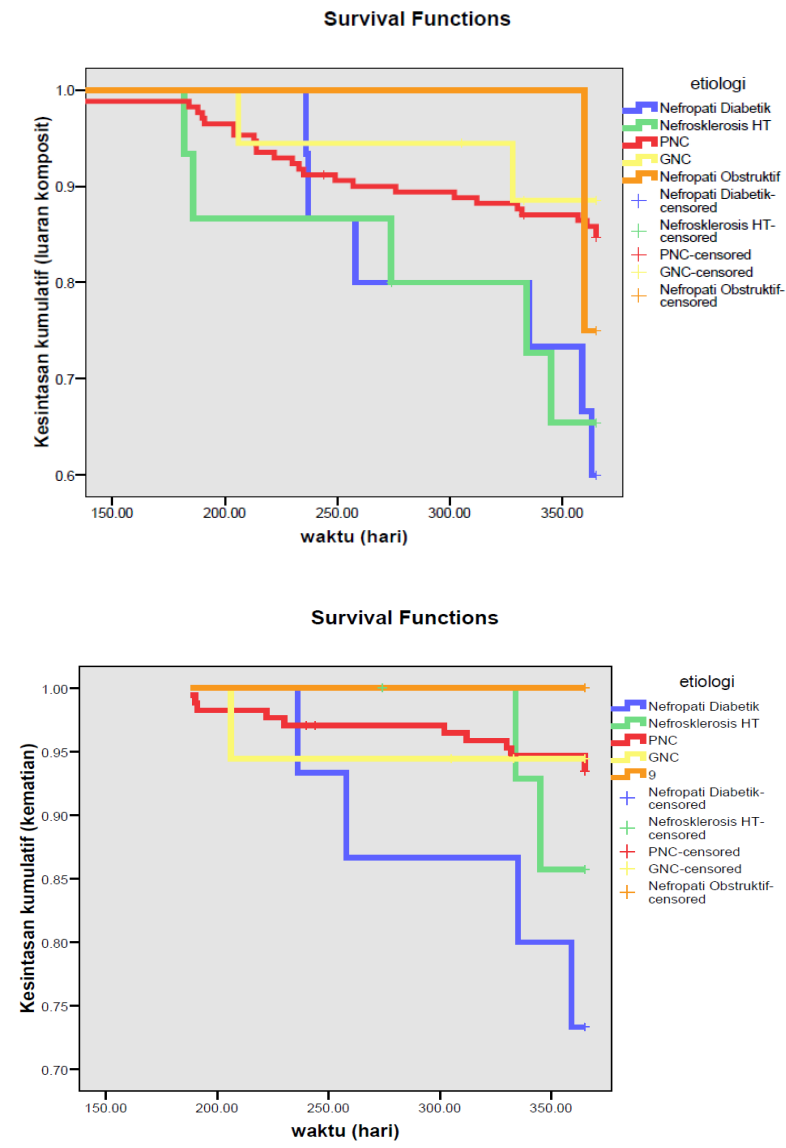

Figure 2. a. The cumulative survival for composite outcome and b. mortality outcome based on etiology of CKD in regular HD patients at Sanglah Hospital Denpasar

Cumulative survival for composite outcome and mortality was done to analyze survival between subjects with risk factors and without risk factors. (Table 1 and Table 2). The risk factors analyzed were hypertension (systolic blood pressure $\geq 140 \mathrm{mmHg}$ and/or diastolic blood pressure $\geq 90 \mathrm{mmHg}$ ), malnutrition defined as $\mathrm{BMI}<23 \mathrm{~kg} / \mathrm{m}^{2}$, hypoalbuminemia $(<3.5 \mathrm{~g} / \mathrm{dl})$, high $\mathrm{Ca}^{2+} \mathrm{xPO}_{4}{ }^{2+}(\geq 55 \mathrm{mg} / \mathrm{dl})$, anemia defined as hemoglobin level $<10 \mathrm{~g} / \mathrm{dl}$, vascular access of arteriovenous fistula, and dialysis membrane surface area of $1.5 \mathrm{~m}^{2}$ vs $1.8 \mathrm{~m}^{2}, \mathrm{Kt} / \mathrm{V}$ value $<1.8$, male gender, and age $>52$ years old (median age of subjects). From all these risk factors, only age older than 52 years old were found to have significantly lower cumulative survival for the composite outcome (Table 2).

From multivariate analysis between 11 risk factors and cumulative survival for composite outcome using
Cox's regression with step-wise backward analysis (10 steps), it was seen that the effect on survival of composite outcome was significantly lower based on etiological risk factor ( $\mathrm{p}=0.03)$, respectively: 1) Diabetic nephropathy $(\mathrm{OR}=1.33 ; 95 \% \mathrm{CI} 0.16$ - 11.06); 2) hypertensive nephrosclerosis (OR $=0.98 ; 95 \% \mathrm{CI}$ 0.11 - 8.47); 3) chronic pyelonephritis $(\mathrm{OR}=0.36$; $95 \%$ CI 0.05 - 2.74); 4) chronic glomerulonephritis $(\mathrm{OR}=0.23 ; 95 \%$ CI 0.02 - 2.66). Risk factors for vascular access (AV Fistula + ) also significantly affected survival of composite outcome $(\mathrm{p}=0.01 ; \mathrm{OR}=0.37$; 95\% CI 0.17 - 0.77). Meanwhile, from a multivariate analysis between 11 risk factors and cumulative survival of mortality using Cox's regression with backward analysis step-wise (9 steps), it appears AV Fistula $(+)$ has higher cumulative survival of mortality $(\mathrm{p}=$ 0.028 ; OR $=0.46 ; 95 \%$ CI 0.23 - 0.92). Subjects aged younger than the median 52 years also had higher cumulative survival for mortality $(\mathrm{p}=0.047$; OR $=0.51$; 95\%CI $0.26-0.99$ ).

\section{Discussion}

The survival rate of this study's subjects did not deviate from the currently available data. Based on The Dialysis Outcomes and Practice Patterns Study (DOPPS), which is a prospective study, observational of 16,720 representative samples of HD patients were followed for 5 years in various countries (Japan, France, Germany, Italy, Spain, the United Kingdom and the United States), the lowest incidence of death in 1 year was found in Japan (6.6\%), followed in Europe (15.6\%) and highest in the United States (21.7\%)..$^{9,10,11}$

Both the causes of death and hospitalization in this study's subjects were also in accordance with currently available data. The 2014 Indonesian Renal Registry (IRR) reported the cause of death in HD patients due to the incidence of $\mathrm{CV}$ is $47 \%$ and as a result of cerebrovascular events is $12 \%{ }^{12}$ The results of this study 
Table 2. Composite Outcome

\begin{tabular}{|c|c|c|c|c|}
\hline Risk Factors & $\begin{array}{l}\text { Cumulative } \\
\text { survival rate }\end{array}$ & Mean survival rate (days) & $\begin{array}{l}\text { Relative } \\
\text { Risk }\end{array}$ & $\mathrm{P} \log$ rank \\
\hline $\begin{array}{l}\text { Hypertensive vs Non-hyper- } \\
\text { tensive }\end{array}$ & $86.3 \%$ vs $79.9 \%$ & $168.51 \pm 5.48$ vs. $163.05 \pm 4.66$ & 0.7 & 0.27 \\
\hline $\begin{array}{l}\text { Malnourished }(\mathrm{BMI}<23 \mathrm{~kg} / \\
\left.\mathrm{m}^{2}\right) \text { vs Non-malnourished }\end{array}$ & $82.9 \%$ vs $80.5 \%$ & $165.38 \pm 4.87$ vs $163.18 \pm 5.72$ & 0.9 & 0.62 \\
\hline $\begin{array}{l}\text { Hypoalbuminemia }(<3.5 \mathrm{~g} / \mathrm{dl}) \\
\text { vs non-hypoalbuminemia }\end{array}$ & $75.0 \%$ vs $83.1 \%$ & $150.79 \pm 15.34$ vs $166.41 \pm 3.57$ & 1.5 & 0.22 \\
\hline $\begin{array}{l}\mathrm{High}\left(\geq 55 \mathrm{mg}^{2} / \mathrm{dl}^{2}\right) \text { vs Low } \\
\mathrm{Ca}^{2+} \mathrm{xPO}_{4}^{2+}\end{array}$ & $80.5 \%$ vs $83.0 \%$ & $166.02 \pm 5.37$ vs $163.90 \pm 4.86$ & 1.1 & 0.71 \\
\hline $\begin{array}{l}\text { Anemia }(\mathrm{Hb}<10 \mathrm{~g} / \mathrm{dl}) \mathrm{vs} \\
\text { non-anemia }(\mathrm{Hb} \geq 10 \mathrm{~g} / \mathrm{dl})\end{array}$ & $77.9 \%$ vs $85.4 \%$ & $162.80 \pm 5.67$ vs $166.02 \pm 4.83$ & 1.5 & 0.15 \\
\hline AVF vs non-AVF & $84.1 \%$ vs $72.5 \%$ & $168,12 \pm 3,56$ vs $149,89 \pm 11,6$ & 0.6 & 0.058 \\
\hline $\begin{array}{l}\text { Dialyser membrane } 1.5 \mathrm{~m}^{2} \mathrm{vs} \\
1.8 \mathrm{~m}^{2}\end{array}$ & $80,3 \%$ vs $84,3 \%$ & $165,19 \pm 4,81$ vs $164,11 \pm 5,31$ & 1.3 & 0.51 \\
\hline $\mathrm{Kt} / \mathrm{V}<1.8$ vs $\geq 1.8$ & $79,9 \%$ vs $85,9 \%$ & $153,6 \pm 4,99$ vs $169,48 \pm 4,86$ & 1.4 & 0.24 \\
\hline Male vs Female & $81,9 \%$ vs $82,1 \%$ & $165,37 \pm 4,28$ vs $163,88 \pm 6,35$ & 1 & 0.99 \\
\hline Age $>52$ vs $\leq 52$ years old & $76,1 \%$ vs $87,6 \%$ & $160,94 \pm 5,47$ vs $168,62 \pm 4,56$ & 2 & $\mathbf{0 . 0 3 5}$ \\
\hline
\end{tabular}

Table 3. Mortality Outcome

\begin{tabular}{|c|c|c|c|c|}
\hline Risk Factors & $\begin{array}{l}\text { Cumulative survival } \\
\text { rate }\end{array}$ & Mean survival rate (days) & $\begin{array}{l}\text { Relative } \\
\text { Risk }\end{array}$ & $\begin{array}{l}\mathrm{P} \log \\
\text { rank }\end{array}$ \\
\hline Hypertensive vs Non-hypertensive & $95.9 \%$ vs $89.9 \%$. & $180.75 \pm 2.79$ vs $175.68 \pm 2.76$ & 0.4 & 0.13 \\
\hline $\begin{array}{l}\text { Malnourished }\left(\mathrm{BMI}<23 \mathrm{~kg} / \mathrm{m}^{2}\right) \text { vs } \\
\text { Non-malnourished }\end{array}$ & $92.2 \%$ vs $92.0 \%$ & $178.14 \pm 2.47$ vs $176.07 \pm 3.81$ & 1 & 0.94 \\
\hline $\begin{array}{l}\text { Hypoalbuminemia }(<3.5 \mathrm{~g} / \mathrm{dl}) \mathrm{vs} \\
\text { non-hypoalbuminemia }\end{array}$ & $87.5 \%$ vs $92.8 \%$ & $176.07 \pm 5.97$ vs $177.54 \pm 2.16$ & 1.9 & 0.27 \\
\hline $\begin{array}{l}\text { High }\left(\geq 55 \mathrm{mg}^{2} / \mathrm{dl}^{2}\right) \text { vs Low } \mathrm{Ca}^{2+} \mathrm{X}- \\
\mathrm{PO}_{4}^{2+}\end{array}$ & $90.9 \%$ vs $92.9 \%$. & $177.52 \pm 3.33$ vs $177.31 \pm 2.69$ & 1.3 & 0.64 \\
\hline $\begin{array}{l}\text { Anemia }(\mathrm{Hb}<10 \mathrm{~g} / \mathrm{dl}) \text { vs non-anemia } \\
(\mathrm{Hb} \geq 10 \mathrm{~g} / \mathrm{dl})\end{array}$ & $89.5 \%$ vs $94.3 \%$ & $176.03 \pm 3.27$ vs $178.37 \pm 2.76$ & 1.8 & 0.17 \\
\hline AVF vs non-AVF & $92.2 \%$ vs $87.5 \%$ & $178,88 \pm 1,90$ vs $170,36 \pm 7,61$ & 0.5 & 0.21 \\
\hline Dialyser membrane $1.5 \mathrm{~m}^{2}$ vs $1.8 \mathrm{~m}^{2}$ & $91,7 \%$ vs $92,1 \%$ & $179,40 \pm 1,97$ vs $174,20 \pm 3,96$ & 1 & 0.93 \\
\hline $\mathrm{Kt} / \mathrm{V}<1.8 \mathrm{vs} \geq 1.8$ & $92,5 \%$ vs $90,6 \%$ & $178,99 \pm 2,25$ vs $174,49 \pm 4,05$ & 0.8 & 0.63 \\
\hline Male vs female & $91,0 \%$ vs $93,6 \%$ & $176,57 \pm 2,61$ vs $178,77 \pm 3,03$ & 1.5 & 0.5 \\
\hline Age $>52$ vs $\leq 52$ years old & $88,1 \%$ vs $95,6 \%$ & $175,59 \pm 3,17$ vs $179,04 \pm 2,44$ & 3 & 0.047 \\
\hline
\end{tabular}


also correspond to reports from the United States Renal Data System (USRDS) which stated that CV disease is also the main cause of death (53.5\%), while septicemia and other infections are the cause of $11.4 \%$ of deaths in the late stages of CKD in the United States between 2012-2014. ${ }^{13}$ The results obtained are based on reports from HD units at Gezira Hospital for Renal Diseases and Surgery in Sudan-Africa in 2011, which stated that infection was the main cause of death ( $45 \%$ ), while the incidence of CV was only $22 \%$ of causes of death. ${ }^{11}$ In general, the results obtained in the study this is in accordance with a survey conducted in 2014 on 3 populations (Asian, European and American populations) as published in Nature. The survey stated that although there were variations among 3 populations, approximately $50 \%$ of the known causes of death were caused by the incidence of $\mathrm{CV} .{ }^{14}$

It was also found that subjects had a cumulative average survival time for a composite outcome of 164.83 \pm 3.57 days, while the cumulative survival rate for mortality was $177.34 \pm 2$ days. In 2014 InaSN tried to see the survival of new patients for 1 year, as stated in the 7th Report of Indonesian Renal Registry. After going through the process of selecting data, there were 3,907 data that could be analyzed with the results that the chances of 1-year survival of hemodialysis patients were $46.7 \%$ with $95 \%$ CI 42.8 - 50,6. ${ }^{15}$ Whereas up to the last IRR (in 2017), there is no publication of survival (survival) of CKD patients who undergo regular HD in Indonesia based on the average survival time as in this study.

This study showed ESRD etiology of diabetic nephropathy was a significant risk factors associated with composite outcome of cardiovascular events, hospitalization, and death, whereas the use of AVF and age $<52$ was particularly associated with higher survival of mortality. Diabetic kidney disease (DKD) have been associated with higher mortality based on current evidence. This might be due to diabetic pa- tients have other traditional risk factors for cardiovascular diseases. DKD can also cause hypercoagulability state, platelet dysfunction, and altered levels of plasma coagulation factors and fibrinolysis mediators. Therefore, the coexistence of DKD and CKD will increase the risk of thrombosis. ${ }^{16}$ The higher mortality outcome of subjects aged $>52$ years old is similar to study by Urrutia et al that showed in addition to the female gender, the age of $>52$ years old was associated with higher mortality. ${ }^{17}$

The use of AVF in this study posed as a significant protective factor for both morbidity and mortality of HD patients. This finding is consistent with prior studies such as the study by Hicks et al from Society for Vascular Surgery that found the mortality risk is lowest in patients with AVF access compared to AV graft and dialysis catheter, in all age groups. ${ }^{18}$ Further assessment of the association of AVF access and mortality was studied by Brown et al, where 1 year mortality was found to be lowest in patients who used AVF since their first HD session (17\%, HR 0.5, CI $95 \% 0.48-0.52, \mathrm{p}<0.001)$, followed by those who used dialysis catheter after AVF failure (25\%, HR 0.66, CI $95 \%$ 0.64-0.68, $\mathrm{p}<0.001$ ), when compared to those who used dialysis catheter since their first HD session (46\%). ${ }^{19}$ A retrospective cohort study by Malas et al on 510.000 hemodialysis patients for 4 years (20062010) showed patients who use AVF access had $35 \%$ lower mortality outcome compared to those with dialysis catheter(adjusted HR 0.65; 95\% CI 0.64-0.66. $\mathrm{p}<0.001) .{ }^{20}$ The use AFV from the first dialysis session had a $23 \%$ lower risk of death even compared to those who use catheter while waiting for fistula maturation (adjusted HR 0,77; 95\% CI 0.76-0.79, $\mathrm{p}<0.001$ ). ${ }^{20}$ This is in alignment with recommendation by $\mathrm{N} / \mathrm{KDOQI}$ (National Kidney Foundation/ Kidney Disease Outcomes Quality Initiative)-2006 which suggest ESRD patients have permanent vascular access 6 months prior to estimate time of dialysis initiation. ${ }^{21}$ 
An interesting relationship was found between hypertension, BMI, and the mortality outcome. In this study, the cumulative survival was found to be higher in the hypertensive group compared to the non-hypertensive group. This phenomenon is what some experts have described as "reverse epidemiology" in HD patients as reported by Nurmohamed SA. et al and Borsboom H. Et al., published in the Netherlands Journal of Medicine. ${ }^{22,23}$ Several large-scale longitudinal cohort studies have shown a paradoxical inverse relationship between blood pressure and mortality in HD patients, where higher blood pressure was associated with lower mortality rate and vice versa. ${ }^{24,25} \mathrm{On}$ the contrary, higher blood pressure had been associated with left ventricular concentric and dilative hypertrophy, both of which have been strongly related to mortality in HD patients. ${ }^{26}$ However, the target of optimal blood pressure in the regular HD patient population is unknown. The recommendations issued by K-DOQI -2005 regarding blood pressure targets in HD patients were pre-dialysis blood pressure $<140 / 90$ $\mathrm{mm} \mathrm{Hg}$ and post-dialysis blood pressure $<130 / 80 \mathrm{~mm}$ Hg. Different recommendations are submitted based on the DOPPS-2012 study, where the target blood pressure of patients with pre-dialysis HD $<130-159$ / 60-99 $\mathrm{mm} \mathrm{Hg}$ and the target of post-dialysis blood pressure $<120-139$ / 70-89 mm Hg. ${ }^{27,28}$ A prospective randomized study is needed to compare the effects of different blood pressure targets on mortality outcomes in regular HD patients.

Meanwhile, subjects with malnutrition (BMI <23 kg / $\mathrm{m}^{2}$ ) were found to have a higher cumulative mortality survival compared to non-malnourished (BMI $\geq 23 \mathrm{~kg}$ $\left./ \mathrm{m}^{2}\right)$ subjects. At first glance, the results of this study are not in accordance with the Reverse Epidemiology concept of BMI risk factors for the outcome of regular HD patient deaths that were obtained in the American and European populations. A comparative study between the effect of BMI on mortality outcomes in the general population and regular HD was published by 24
Kalantar-Zadeh, et al. Data in the general population were taken from Calle et al. (1991) whereas data in the regular HD population were taken from Leavy et al. (2001). Based on the research conclusions, the relative risk of death will increase in accordance with the increase in BMI in the general population, whereas in the regular HD patient population, the relative risk of death will decrease in accordance with the increase of BMI. With the BMI limit of $23 \mathrm{~kg} / \mathrm{m}^{2}$ as the value of the relative risk of death 1.0 (reference) it was found that the overweight category (BMI 25-29.9 kg / m2) in the general population in the study had a relative risk of death 1.1-1.3 ; whereas in regular HD patients the relative risk of death is $0.7-0.9 .{ }^{25}$ However, it should be noted that the regular HD patient population in the Leavy et al study is a combination of data from America and Europe. The research conducted by Wong JS. Et al in the Asian American population got different results, where the effect of $\mathrm{BMI}$ on the relative risk of death if depicted in a U-shape graph, which indicates that with a $23 \mathrm{~kg} / \mathrm{m}^{2}$ BMI limit as a reference; it is found that the relative risk of death will increase according to the BMI increase. ${ }^{29}$

In this study, there was no significant mortality outcome difference between subjects with different dialyzer surface area $(R R=1)$. This can be explained by the different characteristics of the dialyzer used in Sanglah General Hospital. The Nipro ${ }^{\circledR}$ machine (ELISIO-15H) used dialyzers with polyethersulfone material (PES) and surface area of $1.5 \mathrm{~m} 2$, KUF 67 $\mathrm{ml} / \mathrm{hr} / \mathrm{mmHg}$. This dialyzer's clearance of various uremic toxins (at Qb / Qd 300/500 ml/min) was 278 $\mathrm{ml} / \mathrm{min}$ for urea, $259 \mathrm{ml} / \mathrm{min}$ for creatinine, and 241 $\mathrm{ml} / \mathrm{min}$ for phosphate. Meanwhile, the dialyzer used by Fresenius ${ }^{\circledR}$ machines (FXclass-10) was of polysulfone material (PSf) with a surface area of $1.8 \mathrm{~m} 2$, KUF $14 \mathrm{~mL} / \mathrm{hr} / \mathrm{mmHg}$, had the clearance of uremic toxins (at Qb / Qd 300/500 ml/min): $261 \mathrm{ml} / \mathrm{min}$ for urea, $231 \mathrm{ml} / \mathrm{min}$ for creatinine and $210 \mathrm{ml} / \mathrm{min}$ for phosphate. From this, it can be concluded that despite

InaKidney | Vol. II | Is. 2| May-Aug 2019 
the smaller surface area, the $1.5 \mathrm{~m}^{2}$ dialyzer has better performance in uremic toxin clearance. For the influence of dialysis adequacy on mortality, it is found that inadequate $\mathrm{HD}(<1.8)$ has $\mathrm{RR}=0.8$ compared to adequate HD. The phenomenon may be explained in light of the currently acceptable assessment of HD adequacy using blood urea as a surrogate marker for small uremic BM toxins. There has been no development of the use of phosphate as a surrogate marker for the assessment of HD adequacy, whereas phosphate is known as an independent risk factor for the incidence of $\mathrm{KV}$ in dialysis patients. It was found that phosphate clearance did not follow the same diffusion kinetic pattern with urea because of the complex mobilization of phosphate from the body's phosphate stores during dialysis, the mechanism of which are not yet widely known. ${ }^{30}$

\section{Conclusion}

From this study, it can be concluded that cardiovascular events and infection remain the highest cause of morbidity and mortality in dialysis patients. Diabetic nephropathy was highly associated with a lower survival rate for the composite outcome (cardiovascular event, hospitalization, and death) whereas and the use of AVF was associated with a higher survival rate for the composite outcome. The mean age of $<52$ years old and AVF was associated with higher survival for mortality.

\section{References}

1. Panichi V, Scatena A, Migliori M, Marchetti V, Paoletti S, Sara B. 2012. Biomarkers of Chronic Inflammatory State in Uremia and Cardiovascular Disease. Int J Inflam. 2012; 2012: 360147

2. Cohen G, Horl WH. Immune Dysfunction in Uremia - An Update. Toxins (Basel). 2012 Nov;4(11): 962-90.
3. Naqvi SB, Collins AJ. Infectious Complications in Chronic Kidney Disease. Adv Chronic Kidney Dis. 2006 Jul;13(3):199-204.

4. Judd E, Ahmed MI, Harms JC, Terry NL, Sonavane SK, Allon M. Pneumonia in hemodialysis patients: a challenging diagnosis in the emergency room. J Nephrol. 2013;26(6):1128-35

5. Guo H, Liu J, Collins AJ, Foley RN. Pneumonia in incident dialysis patients - the United States Renal Data System. Nephrol Dial Transplant. 2008;23: 680-6

6. Weiner DE, Sarnak MJ. Cardiac Function and Cardiovascular Disease in Chronic Kidney Disease. In: National Kidney Foundation's PRIMER ON KIDNEY DISEASES. $6^{\text {th }}$ Ed. Gilbert SJ, Weiner DE, Gipson DS, Perazella, Tonelli M, editors. Philadelphia: Elsevier; 2014. p 488-96

7. D’Marco L, Bellasi A, Raggi P. 2015. Cardiovascular Biomarkers in Chronic Kidney Disease: state of Current research and Clinical Applicability. Dis Markers. 2015;2015:1-16

8. Usta S, Basbug HS, Cakiroglu Y. High-sensitivity C-reactive protein: Could it be used as a cardiovascular risk predictor in hemodialysis patients? Appl Med Res. 2015; 1(1): 12-15. doi:10.5455/ amr.20150127120710

9. Goodkin DA. Bragg-Gresham JL, Koenig KG, Wolfe RA, Akiba T, Andreucci KG, et al. Association of Comorbid and Mortality in Hemodialysis Patients in Europe, Japan, and the United States: The Dialysis Outcomes and Practice Patterns Study (DOPPS). J Am Soc Nephrol. 2003;14:3270-7

10. Nguyen B, Fukuuchi F. Survival rates and cause of death in Vietnamese chronic hemodialysis patients. Ren Replace. 2017:3(22);1-10

11. Elsharif ME. Mortality Rate of Patients with EndStage Renal Disease on Regular Hemodialysis: A Single-Center Study. Saudi J Kidney Dis Transpl. 2011; 22(3):594-6.

12. Indonesian Society of Nephrology. The $8^{\text {th }}$ Annual Report of Indonesia Renal Registry (IRR). Bandung: InaSH; 2015.

13. United States Renal Data System (USRDS) Annual Data Report.. Cardiovascular Disease in patients with ESRD. 2016: 2; S465-S479. 
14. De Jager DJ, Vervloet MG, Dekker FW. Noncardiovaskular mortality in CKD: an epidemiological perspective. Nat Rev Nephrol. 2014:10;208-14

15. Indonesian Society of Nephrology. $7^{\text {th }}$ Annual Report of Indonesia Renal Registry (IRR). Bandung: InaSH; 2014

16. Palsson R, Patel UD. Cardiovascular Complications of Diabetic Kidney Disease. Adv Chronic Kidney Dis. 2014: 21(3): 273-80

17. Urrutia JD, Gayo WS, Bautista, Baccay EB. 2015. Survival Analysis of Patients with End-Stage Renal Disease. J Physics: Conference series. 2015; 622:110

18. Hicks CW, Canner JK, Arhuidese I, Zarkowsky DS, Qazi U, Reifsnyder T, et al. Mortality benefits of different hemodialysis access types are age dependent. J Vasc Surg. 2015; 61:449-456

19. Brown RS, Patibandla BK, Goldfarb-Rumyantzev AS. The Survival Benefit of "Fistula First, Catheter Last" in Hemodialysis Is Primarily Due to Patient Factors. J Am Soc Nephrol. 2017; 28:645-52

20. Malas MB, Canner JK, Hicks CW, Arhuidese IJ, Zarkowsky DS, Qazi U, et al. 2015. Trends in Incident hemodialysis Access and Mortality. JAMA Surg. 2015;150(5):441-8

21. National Kidney Foundation. 2006 Updates Clinical Practice Guidelines and Recommendations: Clinical Practice Guidelines for Vascular Access. New York: National Kidney Foundation, Inc; 2006.

22. Nurmohamed SA. Nube MJ. 2005. Reverse epidemiology: paradoxical observations in hemodialysis patients. Neth J Med; 63(10):376-381

23. Borsboom H, Smans L, Cramer MJM. 2005. Longterm blood pressure monitoring and echocardiographic findings in patients with end-stage renal disease: reverse epidemiology explained? Neth J Medical; 63 (10):399-406

24. Zager PG, Nikolic J, Brown RH, Campbell MA, Hunt WC, Peterson D, et al. 1998. "U" curve association of blood pressure and mortality in hemodialysis patients. Kidney Internasional; 54:561-569.

25. Kalantar-Zadeh K, Block G, Humpreys MH, Kopple JD. Reverse epidemiology of cardiovascular risk factors in maintenance dialysis patients. Kid- ney Int. 2003; 63:793-808

26. Parfrey PS, Foley RN, Harnet JD. Outcome and risk factors for left ventricular disorders in chronic uremia. Nephrol Dial Transplant. 1996;11:12771285

27. Robinson BM, Tong L, Zhang J, Wolfe RA, Goodkin DA, Greenwood RN, et al. Blood Pressure Levels and Mortality Risk among Hemodialysis Patients: Results from the Dialysis Outcomes and Practice Pattern Study. Kidney Int. 2012; 82(5): 570-580.

28. Turner JM, Peixoto SJ. Blood pressure targets for hemodialysis patients. Kidney Int. 2017; 92: 816823.

29. Wong JS, Port FK, Hulbert-Shearon TE, Carroll CE, Wolfe RA, Agodoa LYC, et al. Survival advantage in Asian American end-stage renal disease patients. Kidney Int. 1999; 55:2515-2523

30. Spalding EM, Chamney PW, Farrington K. Phosphate kinetics during hemodialysis: Evidence for biphasic regulation. Kidney Int. 2002;61:655-667 